\title{
INTRACRANIAL MENINGIOMAS
}

\section{Magnetic resonance imaging findings in 78 cases}

\author{
Emerson L. Gasparetto', Claudia da Costa Leite', Leandro T. Lucato', \\ Cristiano Ventorin de Barros', Sueli K.N. Marie², Pedro Santana², \\ Paulo Henrique Pires de Aguiar², Sérgio Rosemberg ${ }^{3}$
}

\begin{abstract}
Objective: To present the magnetic resonance (MR) imaging findings of 78 patients with meningiomas diagnosed in a single institution. Method: 78 patients with histological proven intracranial meningioma were studied. There were 52 female and 26 male patients (median=56 years). All MR imaging examinations were performed with 1.5-T MR imaging unit with standard protocol. The images were studied by two neuroradiologists, who reached the decisions regarding the findings by consensus. Results: Most of the tumors showed low signal on T1- $(60 \%)$ and high signl on T2- $(68 \%)$ and FLAIR $(69 \%)$ weighted images. Also, the lesions showed heterogeneous signal on T1 (60\%), T2 (68\%) and FLAIR (64\%) sequences. After contrast administration, $83 \%(n=65)$ of the tumors presented acentuated and $17 \%(n=13)$ showed moderate enhancement. The tumors were located in the frontal lobe in $44 \%$ of the cases, in the parietal lobe in $35 \%$, the occipital lobe in $19 \%$ and the temporal lobe in $12 \%$ of the patients. Areas of vasogenic edema around the tumors were seen in $90 \%$ of the cases. Twenty six per cent of the cases showed bone infiltration, and the dural tail sign was seen in $59 \%$ of the tumors. Conclusion: Intracranial meningiomas usually show heterogeneous low signal on T1- and high signal on T2-weighted and FLAIR images, with intense enhancement after contrast administration. The frontal and parietal lobes are commonly affected. In addition, brain edema, dural tail sign and bone infiltration are the most frequent associated findings.
\end{abstract}

KEY WORDS: meningioma, magnetic resonance imaging, brain tumors.

\section{Meningiomas intracranianos: achados de ressonância magnética em 78 casos}

RESUMO - Objetivo: Apresentar os achados de ressonância magnética (RM) de 78 pacientes com meningioma intracraniano diagnosticados numa única instituição. Método: 78 pacientes com diagnóstico histológico de meningioma intracraniano foram estudados. Cinqüenta e dois eram femininos e 26 masculinos (mediana=56 anos). Todos os exames de RM foram realizados num aparelho de 1.5 Tesla, com protocolo padrão. As imagens foram avaliadas por dois neurorradiologistas, os quais estabeleceram os achados por consenso. Resultados: A maioria dos tumores apresentou baixo sinal em T1 (60\%) e alto sinal em T2 (68\%) e FLAIR (69\%). Além disso, as lesões demonstraram sinal heterogêneo em T1 (60\%), T2 (68\%) e FLAIR (64\%). Após a administração intravenosa de contraste, 83\% dos tumores apresentaram realce acentuado e $17 \%$ moderado. Os tumores estavam localizados no lobo frontal em $44 \%$ dos casos, no parietal em 35\%, no occipital em $19 \%$ e no lobo temporal em $12 \%$ dos casos. Áreas de edema vasogênico foram observadas em $90 \%$ dos pacientes. Vinte e seis por cento dos casos apresentaram sinais de infiltração óssea e o sinal da cauda dural foi visto em $59 \%$ dos tumores. Conclusão: Meningiomas intracranianos em geral apresentam sinal heterogêneo, baixo em T1 e alto em T2 e FLAIR, com intenso realce pelo contraste. Os lobos frontais e parietais são com freqüência acometidos. Além disso, edema vasogênico, sinal da cauda dural e infiltração óssea são os achados associados mais comuns.

PALAVRAS-CHAVE: meningioma, ressonância magnética, tumores cerebrais.

Meningiomas are the most common primary nonglial intracranial tumors ${ }^{1-3}$. This neoplasm affects more frequently patients in middle and late decades of life, with a strong female prediction $(2: 1)^{1-3}$. The classical appearance on the computed tomography (CT) scans and magnetic resonance (MR) imaging usually leads to a correct diagnosis of meningiomas. The CT scan usually demonstrates an extra-axial mass hypo- or isodense, with intense enhancement after contrast administration ${ }^{1,4,5}$.

On MR imaging, the tumor has variable signal, being most commonly iso- or hypointense on T1-weight-

Departments of Radiology ${ }^{1}$, Neurology ${ }^{2}$ and Pathology ${ }^{3}$, University of São Paulo School of Medicine, São Paulo SP, Brazil.

Received 8 November 2006, received in final form 27 March 2007. Accepted 27 April 2007.

Dr. Emerson L. Gasparetto - Rua Lopes Trovão 44 / 1104 - 24220-071 Niterói RJ - Brasil. E-mail: egasparetto@gmail.com 
ed images and hyperintense on T2-weighted images. However, the lesions may present heterogeneous signal on T1- and more evident on T2-weighted images. After gadolinium administration, meningiomas show intense enhancement, which may be heterogeneous in some cases ${ }^{1,4}$. Other findings as adjacent edema, cystic foci, calcifications and hyperostosis are also demonstrated in some patients with megingiomas.

We present the MR imaging findings of 78 patients with meningiomas diagnosed in a single institution.

\section{METHOD}

This retrospective study included 78 patients with histological proven intracranial meningioma, which were diagnosed between 2001 and 2005. There were 52 female and 26 male patients, with ages raging between 23 and 81 years (median $=56$ years, standard deviation=12.7). All patients underwent surgical biopsy or resection of the tumors, and the histological diagnosis of meningioma was defined based on the World Health Organization criteria ${ }^{6}$.

All MR imaging examinations were performed with 1.5T MR imaging unit (Signa Horizon LX; GE Medical Systems, Milwaukee, Wis). The MR imaging protocol included the following sequences: T1-weighted images (repetition time (TR) ms/echo time (TE) ms, 466/19), T2-weighted images (TR/ $T E=4500 / 120 \mathrm{~ms}$; echo train length (ETL), eight), and fluid-attenuated inversion recovery images (FLAIR) (TR/TE/inversion time, $11002 / 148 / 2200 \mathrm{~ms}$ ). The slice thickness was $5 \mathrm{~mm}$, and the field of view (FOV) varied between 18 and $24 \mathrm{~cm}$. We also obtained axial, coronal, and sagittal T1weighted images after the administration of $0.1 \mathrm{mmol}$ per kilogram of body weight of a gadolinium chelate. All the exams were recorded in hard disks, zip disks or compact disks. In several cases, only some images of each sequence were available, but in these cases they were enough for the study following our imaging protocol.
The images were studied by two neuroradiologists, who reached the decisions regarding the findings by consensus. The following features were analyzed: signal intensity and presence of homogeneity or heterogeneity in all obtained sequences, presence of contrast enhancement, location of the lesion and presence of brain edema, foci of calcification (low signal on $\mathrm{T} 2{ }^{*}$-weighted gradient-echo images and correlation with $\mathrm{CT}$ ), hemorrhage or cystic components in the tumors. The edema and the contrast enhancement were classified as discrete, moderated and accentuated, according with the extension of the edema and intensity of the contrast enhancement. Evidence of bone infiltration and dural tail sign were also studied.

\section{RESULTS}

Considering the signal intensity on T1-weighted images, $60 \%(n=47)$ of the tumors showed low signal, 36\% $(n=28)$ intermediate signal and $4 \%(n=3)$ had high signal. In 47 cases $(60 \%)$ the lesions were heterogeneous on T1-weighted images, and in 31 $(40 \%)$ they were homogeneous. In the FLAIR sequences, $69 \%(n=54)$ of the tumors had high signal, $22 \%(n=17)$ intermediate signal, and $9 \%(n=7)$. In most of the cases $(64 \%)$, the lesions were heterogeneous on FLAIR sequences. On the T2-weighted images, $68 \%(n=53)$ of cases showed high signal, $26 \%$ $(n=20)$ intermediate signal and $4 \%(n=5)$ low signal. Most of the tumors were heterogeneous (68\%) on T2-weighted images.

After contrast administration, $83 \%(n=65)$ of the tumors present accentuated and $17 \%(n=13)$ showed moderate enhancement. The contrast enhancement was heterogeneous in most of the patients (64\%).

Taking in account the tumor location, the meningioma was located in the frontal lobe in $44 \%(n=34)$ of the cases, in the parietal lobe in $35 \%(n=27)$, the

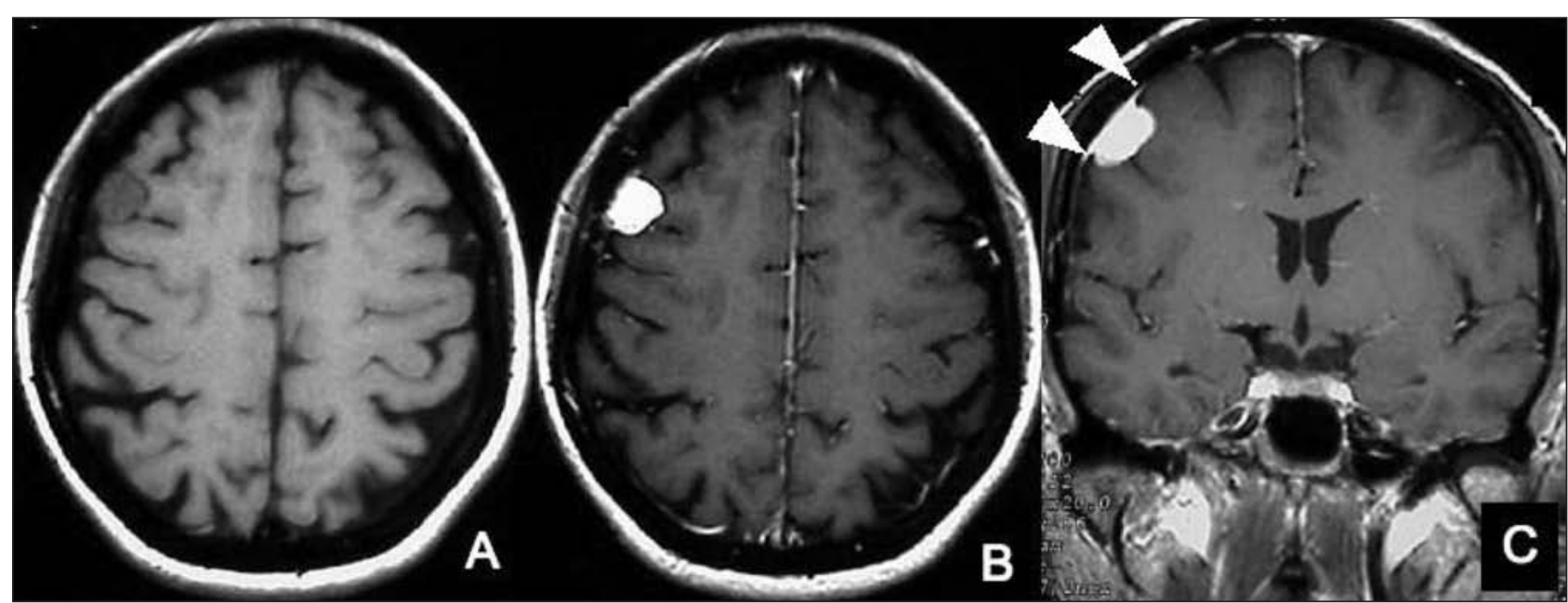

Fig 1. Axial T1-weighted pre- (A) and post-contrast (B) and sagital T1-weighted post-contrast (C) MR imaging show a right frontal extra-axial mass with low signal and intense contrast enhancement. Note the "dural tail" sign (arrows). 


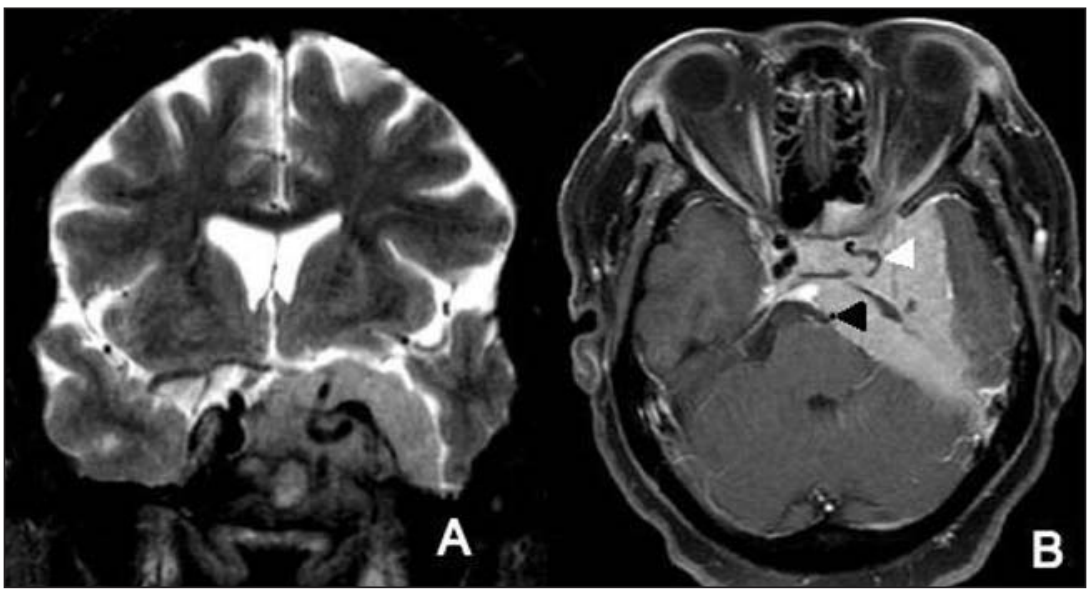

Fig 2. Coronal T2-weighted (A) and axial T1-weighted post-contrast (B) MR imaging demonstrate a left para-selar mass isointense to the cortex on T2-weighted images and with enhancement after contrast administration. The lesion is involving and narrowing the left internal carotid (white arrow) and basilar artery (black arrow), as well as compressing the brain stem, left cerebellar hemisphere and left temporal lobe.

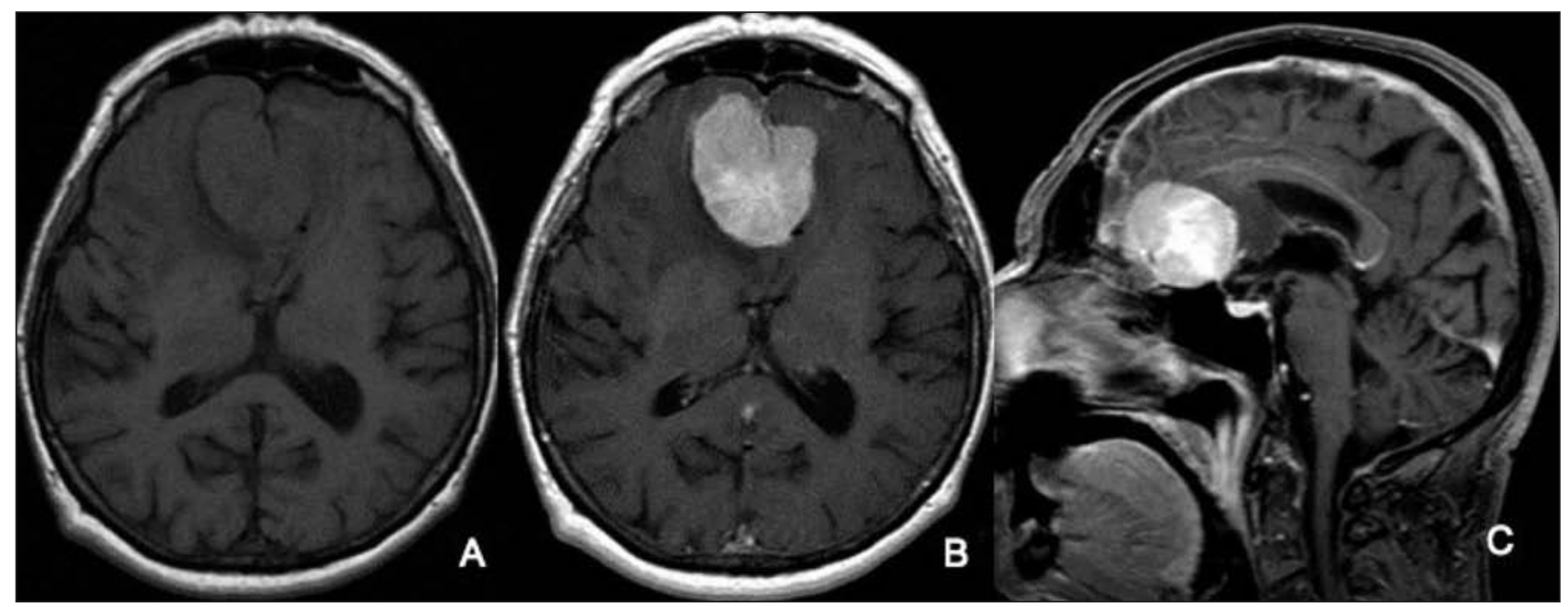

Fig 3. Axial T1-weighted pre- (A) and post-contrast (B) and sagital T1-weighted post-contrast (C) MR images show a frontal extraaxial mass at the olfactory groove with isointense signal to the cortex on T1-weighted images and intense contrast enhancement. The lesion is compressing the frontal lobes, lateral ventricles and corpus callosum and there is an area of low signal on the right frontal white matter representing vasogenic edema.

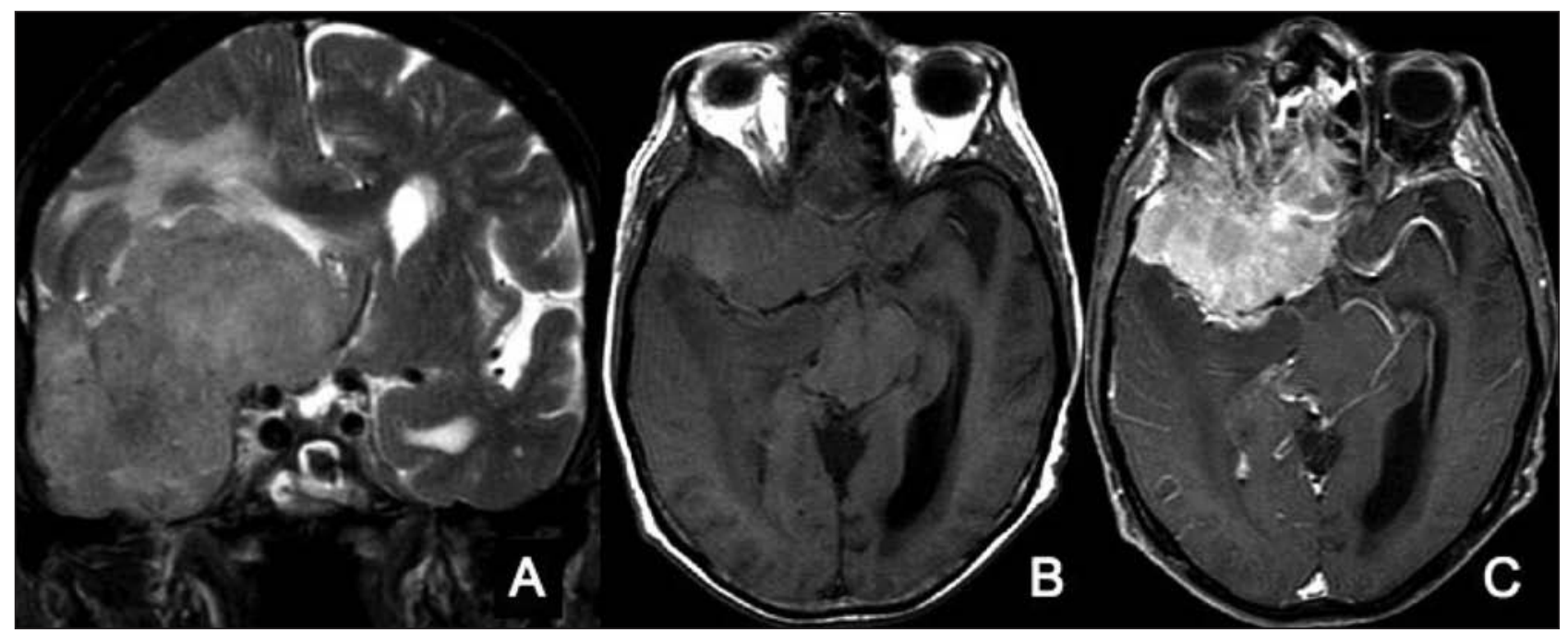

Fig 4. Coronal T2-weighted (A) and axial T1-weighted pre- (B) and post-contrast (C) MR imaging demonstrate a right para-selar mass isointense to the cortex on T1- and T2-weighted images and presenting intense enhancement after contrast administration. The lesion is compressing adjacent structures, involving and narrowing the right middle cerebral artery and causing middle line shift. Note the discrete lateral ventricles enlargement. 
occipital lobe in $19 \%(n=24)$ and the temporal lobe in $12 \%(n=9)$ of the patients. Lesions at the ventricles, posterior fossa and para-selar region were seen in four, three and three cases, respectively.

Areas of vasogenic edema around the tumors were seen in $90 \%(n=70)$ of the cases. The edema was considered discrete in $50 \%(n=39)$ of the cases, moderated in $37 \%(n=29)$ and severe in $23 \%(n=10)$ of the patients. Foci of hemorrhage were observed only in three tumors, and areas suggestive of cystic components in six cases. Foci of calcification were observed also in six patients and evidence of bone infiltration in $26 \%(n=20)$ of the patients. The dural tail sign was seen in $59 \%(n=46)$ of the tumors.

Figures 1 to 4 illustrate our findings.

\section{DISCUSSION}

There are several studies discussing the signal characteristics of the meningiomas at the MR imaging. The signal intensity of the tumor mass may be rather variable on both T1-, T2-weighted and FLAIR images $^{1,4,7}$. On T1, most tumors are isointense to the cortical grey matter (from $56 \%$ to $94 \%$ ). Hypointense meningiomas account from $20 \%$ to $48 \%$, and hyperintense tumors on T1-weighted images are rare. On T2-weighted images, about $50 \%$ of the tumors remain isointense with the brain cortex. Hypointense tumors are less common, from $4 \%$ to $18 \%$, whereas hyperintense lesions account for $35 \%$ to $44 \% \%^{1,4}$. In the present series, on T1-weighted images, $60 \%$ of the tumors showed low signal, 36\% intermediate signal and $4 \%$ had high signal. On the $\mathrm{T} 2$-weighted images, most tumors (68\%) were hyperintense and $26 \%$ isointense to the cortical grey matter.

Meningiomas characteristically show intense enhancement after contrast administration both on CT scans and MR imaging ${ }^{1,4,8}$. This enhancement may be either central or ring-like, and it is explained to the fact that meningiomas capillaries have no bloodbrain barrier. The tumor enhancement in patients with meningiomas may help to identify anatomic boundaries of larger lesions that may be isointense to the brain on T1-weighted images'. In our study, all the meningiomas showed enhancement after contrast administration, which was accentuated in $83 \%$ of the cases, and heterogeneous in $64 \%$ of the patients.

Cystic foci, hemorrhage and calcifications may be seen in approximately $20 \%$ of the patients with meningiomas ${ }^{1}$. In the present study, cystic components and foci of calcification and hemorrhage were seen in $8 \%, 8 \%$ and $4 \%$ of the patients, respectively.
The presence of brain edema is frequently reported in patients with meningiomas ${ }^{1,5,7}$. Several studies tried to elucidate the tumor characteristics associated with the presence of edema. The tumor size, location, signal intensity on T2-weighted images and invasive pattern of brain-tumor interface were related to the presence of edema in patients with meningiomas. However, the histological subtypes were not related with the this finding ${ }^{5,7}$. In the present study, $90 \%$ of the patients showed brain edema, which more commonly was discrete $(50 \%)$.

Nakau et al. ${ }^{9}$ studied the correlation of the MR imaging and histopathological findings in nine cases of meningiomas with dural tail sign. They suggested that tumor cell nests in the dura mater of those patients, making the surgical resection of these areas mandatory. Almost $35 \%$ of the patients with meningiomas may present the dural tail signal on post-contrast T1-weighted images ${ }^{1}$. In the present series this sign was seen frequently, being identified in $59 \%$ of the patients.

Our study shows that meningiomas usually present heterogeneous signal intensity in all the pre-contrast sequences, demonstrating more commonly low signal on T1- (60\%) and high signal on T2-weighted $(69 \%)$ and FLAIR images (68\%). Most of the tumors shows accentuated enhancement after contrast administration $(83 \%)$, which is frequently heterogeneous $(64 \%)$. The frontal and parietal lobes were the most commonly affected regions (44\% and 35\% respectively). Edema was seen in $90 \%$ of the cases, which usually was discrete (50\%). The dural tail sign was frequent in our series ( $59 \%$ ), as well as $29 \%$ of the tumors showed evidence of bone infiltration. Foci of cystic components, hemorrhage and calcifications were rarely seen.

The present study has several limitations. First, this retrospective study was based on the analysis of images recorded in hard disks, zip disks and compact discs. As a result, in several cases, only a few images of each sequence were recorded and analyzed. Finally, only cases with histological diagnosis of meningioma were included in the study, which could result in bias of selection, as some patients with lesions presenting imaging findings highly suggestive of meningiomas stay for long periods in the followup evaluation without surgical intervention.

In conclusion, intracranial meningiomas usually show heterogeneous low signal on T1- and high signal on T2-weighted and FLAIR images, with intense enhancement after contrast administration. The 
frontal and parietal lobes are commonly affected. In addition, brain edema, dural tail sign and bone infiltration are the most frequent associated findings.

\section{REFERENCES}

1. Atlas SW. Magnetic resonance imaging of the brain and spine. Philadelphia: Lippincott Willians \& Wilkins, 2002.

2. Claus EB, Bondy ML, Schildkraut JM, Wiemels JL, Wrensch M, Black PM. Epidemiology of intracranial meningioma. Neurosurgery 2005;57:1088-1095.

3. Engelhard HH. Progress in the diagnosis and treatment of patients with meningiomas. Part I: diagnostic imaging, preoperative embolization. Surg Neurol 2001;55:89-101.

4. Maiuri F, Iaconetta G, de Divitiis O, Cirillo S, Di Salle F, De Caro ML.
Intracranial meningiomas: correlations between MR imaging and histology. Eur J Radiol 1999;31:69-75.

5. Souto AA, Chimelli L, Takya CM, Souza JM, Fonseca AL, Silva LF. Brain edema in meningiomas: radiological and histological factors. Arq Neuropsiquiatr 2002;60:807-817.

6. Kleihues P, Cavenee WK. Pathology and genetics of tumours of the nervous system. Lyon: IARC Press, 2000.

7. Nakano T, Asano K, Miura H, Itoh S, Suzuki S. Meningiomas with brain edema: radiological characteristics on MRI and review of the literature. Clin Imaging 2002;26:243-249.

8. Yang S, Law M, Zagzag D, et al. Dynamic contrast-enhanced perfusion MR imaging measurements of endothelial permeability: differentiation between atypical and typical meningiomas. Am J Neuroradiol 2003;24:1554-1559.

9. Nakau H, Miyazawa T, Tamai S, et al. Pathologic significance of meningeal enhancement ("flare sign") of meningiomas on MRI. Surg Neurol 1997;48:584-590. 